\title{
Effect of nature of dietary lipids on European sea bass morphogenesis: implication of retinoid receptors
}

\author{
Laure Villeneuve $^{1 *}$, Enric Gisbert ${ }^{2}$, Jose L. Zambonino-Infante ${ }^{1}$, Patrick Quazuguel ${ }^{1}$ and Chantal L. Cahu ${ }^{1}$ \\ ${ }^{1}$ UMR1067, Nutrition Aquaculture Génomique, IFREMER, 29280 Plouzané, France \\ ${ }^{2}$ Centre d'Aqüicultura, Institut de Recerca i Tecnologia Agroalimentaries (IRTA), Aptat. Correus 200, 43540 Sant Carles de la Ràpita, \\ Tarragona, Spain
}

(Received 8 March 2005 - Revised 6 June 2005 - Accepted 21 June 2005)

\begin{abstract}
The effect of the nature and form of supply of dietary lipids on larval development was investigated in European sea bass larvae, by considering the expression of several genes involved in morphogenesis. Fish were fed from 7 to $37 \mathrm{~d}$ post-hatch with five isoproteic and isolipidic compound diets incorporating different levels of EPA and DHA provided by phospholipid or neutral lipid. Phospholipid fraction containing 1.1\% (PL1 diet) to $2.3 \%$ (PL3 diet) of EPA and DHA sustained good larval growth and survival, with low vertebral and cephalic deformities. Similar levels of EPA and DHA provided by the neutral lipid fraction were teratogenic and lethal. Nevertheless, dietary phospholipids containing high levels of DHA and EPA (PL5 diet) induced cephalic $(8.5 \%)$ and vertebral column deformities $(35.3 \%)$ adversely affecting fish growth and survival; moreover, a down-regulation of retinoid X receptor $\alpha$ $(R X R \alpha)$, retinoic acid receptor $\alpha$, retinoic acid receptor $\gamma$ and bone morphogenetic protein-4 genes was also noted in PL5 dietary group at day 16. High levels of dietary PUFA in neutral lipid (NL3 diet) first up-regulated the expression of $R X R \alpha$ at day 16 and then down-regulated most of the studied genes at day 23, leading to skeletal abnormalities and death of the larvae. A moderate level of PUFA in neutral lipids up-regulated genes only at day 16 , inducing a lesser negative effect on growth, survival and malformation rate than the NL3 group. These results showed that retinoid pathways can be influenced by dietary lipids leading to skeletal malformation during sea bass larvae development.
\end{abstract}

Phospholipids: Neutral lipids: Dicentrarchus labrax larvae: Skeletal malformations: Retinoic acid receptors

Around $30 \%$ of marine fish larvae reared in commercial hatcheries exhibit morphological and skeletal deformities (Andrades et al. 1994; Boglione et al. 2001). These abnormalities (e.g. lordosis, scoliosis, vertebral fusion and compression, lower jaw deformity, reduced maxillary bones, a reduced or incomplete operculum) lead to a depreciated market price for the fish farmer, a setback to the quality image of aquaculture and represent one of the most important bottlenecks in actual marine aquaculture.

Different factors, genetic and environmental, are involved in the formation of the skeleton and are supposed to be responsible for the appearance of skeletal abnormalities during larval development. Among them, the influence of diet composition on larval malformation has recently been shown experimentally. Several studies have demonstrated that nutrients are responsible for the appearance of skeletal deformities when their level and/ or form of supply in the diet are inappropriate (ZamboninoInfante et al. 1997; Cahu et al. 2003a). These perturbations in development are linked to an action of these molecules on target genes involved in morphogenesis, such as the Hox and sonic hedgehog $(s h h)$ family genes. For example, a lack or an excess of some vitamins, such as vitamin A, is known to have teratogenic effects on the development of mammals, birds, amphibians and fish through disturbance of the normal expression of morphogenetic genes (Ogura \& Evans, 1995; Suzuki et al. 1998; Ross et al. 2000; Villeneuve et al. 2005). Dietary lipid levels and form affect the growth and the malformation rate of marine fish larvae (Cahu et al. 2003b).

Lipids are the main energy source in developing larvae and the lipid requirements of marine fish larvae have been extensively studied. Particular attention has been paid to phospholipids and PUFA (Sargent et al. 1999). It has been reported recently that a diet containing $19 \%$ lipids with almost $9 \%$ phospholipids induced good growth in European sea bass first-feeding larvae (Cahu et al. $2003 b$ ). In fact, the former authors demonstrated that the appearance of skeletal deformities in European sea bass during early development was linked more to the proportion of dietary phospholipids:neutral lipids than to the total dietary lipid content. Marine fish are unable to synthesize $n$ - 3 PUFA such as EPA and DHA, which are particularly important as they occur in large amounts in fish cell membranes. The optimal level of these essential dietary components for marine fish is known to be around $3 \%$ of DM for EPA + DHA (Sargent et al. 1999).

In addition to their nutritional role, fatty acids are essential biological components able to rapidly modulate the transcription of genes involved in their metabolism (Kliewer et al. 1997). This modulation involves nuclear hormone receptors, the PPAR. 
These receptors are known to form heterodimers with other cellular receptors called retinoid $\mathrm{X}$ receptors (RXR), which are involved in the retinoid pathways (Ross et al. 2000). This heterodimerization indicates that the retinoids and the peroxisome proliferator signalling pathways converge through the direct interaction of their respective nuclear receptors (Bonilla et al. 2000). These dimers regulate the expression of target genes by binding to DNA sequence elements (Ross et al. 2000) present in the regulatory regions of a variety of genes involved in lipid metabolism, energy balance or morphogenesis (Kliewer et al. 1997; Balmer \& Blomhoff, 2002). The retinoid pathways control the expression of morphogenetic genes through the action of two types of nuclear receptors, the retinoic acid receptors (RAR) and the RXR. These morphogenetic genes involve many gene families, such as Hox genes (Krumlauf, 1994), bone morphogenetic protein $(B M P)$ genes (Sasagawa et al. 2002) and insulin-like growth factor $(I G F)$ genes (Fu et al. 2001). A modification in the equilibrium between the nuclear receptors, such as an increase of PPAR, results in the perturbation of the number of receptors involved in retinoid pathways (Bonilla et al. 2000). Thus, the nature (phospholipids $v$. neutral lipids) and level of dietary lipids might be able to modify the expression of certain receptors involved in growth, differentiation and cellular homeostasis from the earlier-mentioned signalling pathways (Bonilla et al. 2000). The aim of the present study was to evaluate the effect of the nature (phospholipid $v$. neutral lipid) and level of $n$-3 PUFA from the dietary lipid supply on: (i) the appearance of skeletal abnormalities; (ii) the regulation of several genes $(R X R \alpha$, $R A R \alpha, R A R \gamma, B M P 4$ and $I G F-I)$ directly or indirectly involved in the retinoid pathways of European sea bass larvae.

\section{Materials and methods}

\section{Animals and diets}

European sea bass (Dicentrarchus labrax) larvae (3 d old) were obtained from the Ecloserie Marine de Gravelines (Gravelines, France) and shipped to the Fish Nutrition Laboratory at the Ifremer (Centre de Brest). Fish were acclimatized and divided into fifteen 35-litre cylindroconical fibreglass tanks (2100 larvae/ tank) at a initial density of 60 larvae/l. Tanks were supplied with running sea water, which had been previously filtered through a sand filter, then passed successively through a tungsten heater and a degassing column packed with plastic rings. Throughout the experiment, the water temperature and salinity were $20^{\circ} \mathrm{C}$ and $35 \%$, respectively, and the $\mathrm{O}_{2}$ level was maintained above $6 \mathrm{mg} / \mathrm{l}$ by setting the water exchange of the tank at $30 \%$ per h (flow rate: $0 \cdot 18 \mathrm{l} / \mathrm{min}$ ). Photoperiod was $24 \mathrm{~h}$ light/ $0 \mathrm{~h}$ dark and maximum light intensity was $9 \mathrm{~W} / \mathrm{m}^{2}$ at the water surface. All animal procedures and handling were conducted in compliance with the Guide for the Care and Use of Laboratory Animals (National Research Council, 1985).

At $4 \mathrm{~d}$ post-hatch (dph), larvae were divided into five experimental groups (three replicates per group) that were fed from first feeeding $(7 \mathrm{dph})$ with experimental compound microdiets. Five isonitrogenous and isolipidic diets (Table 1) were formulated to incorporate different levels of PUFA, which differed in their form of supply: phospholipids or neutral lipids. Fishmeal, naturally containing $17 \%$ lipid, was defatted in order to control the experimental dietary lipid composition by only the addition of oils. Fishmeal was defatted in the presence of dichloromethane for $20 \mathrm{~min}$ at $40^{\circ} \mathrm{C}$, rinsed and dried until complete solvent evaporation. Among lipid

Table 1. Composition of the experimental compound microdiets

\begin{tabular}{|c|c|c|c|c|c|}
\hline & \multicolumn{5}{|c|}{ Experimental diets } \\
\hline & PL1 & PL3 & PL5 & NL1 & NL3 \\
\hline \multicolumn{6}{|l|}{ Ingredients* (g/kg DM) } \\
\hline Defatted fishmeal & & & 510 & & \\
\hline Hydrolysed fishmeal (CPSP) & & & 140 & & \\
\hline Cod-liver oil & 0 & 0 & 0 & 7 & 14 \\
\hline Marine lecithin & 7 & 14 & 21 & 0 & 0 \\
\hline Soya lecithin & 14 & 7 & 0 & 14 & 7 \\
\hline Vitamin mixture† & & & 80 & & \\
\hline Mineral mixture & & & 40 & & \\
\hline Betaine & & & 20 & & \\
\hline \multicolumn{6}{|l|}{ Proximate composition (\%) } \\
\hline Proteins $(\mathrm{N} \times 6.25)$ & $59 \cdot 9$ & $61 \cdot 6$ & $60 \cdot 4$ & $58 \cdot 7$ & $59 \cdot 6$ \\
\hline Lipids & $16 \cdot 4$ & $16 \cdot 7$ & $16 \cdot 7$ & $17 \cdot 1$ & $18 \cdot 2$ \\
\hline \multicolumn{6}{|l|}{ Including: } \\
\hline Phospholipids & $13 \cdot 2$ & $13 \cdot 0$ & $12 \cdot 1$ & $11 \cdot 1$ & $8 \cdot 1$ \\
\hline $\mathrm{EPA}+\mathrm{DHA}$ & $1 \cdot 1$ & $2 \cdot 3$ & $4 \cdot 8$ & 0.3 & 0.4 \\
\hline Neutral lipids & $4 \cdot 8$ & 3.8 & $3 \cdot 0$ & $6 \cdot 2$ & $11 \cdot 0$ \\
\hline$E P A+D H A$ & 0.3 & 0.3 & 0.3 & $1 \cdot 3$ & $2 \cdot 6$ \\
\hline Ash & $17 \cdot 4$ & $17 \cdot 0$ & $16 \cdot 8$ & $15 \cdot 6$ & $15 \cdot 6$ \\
\hline Moisture & $6 \cdot 8$ & $6 \cdot 3$ & $7 \cdot 4$ & $6 \cdot 5$ & $6 \cdot 4$ \\
\hline Energy $(\mathrm{kJ} / \mathrm{kg}) \S$ & 1618 & 1658 & 1638 & 1624 & 1681 \\
\hline
\end{tabular}

* All dietary ingredients were obtained commercially. Fishmeal (La Lorientaise, Lorient, France), hydrolysed fishmeal (CPSP, Soluble Fish Protein Concentrate; Sopropêche, Boulogne sur Mer, France), cod-liver oil (La Lorientaise), marine lecithin (LC60, Phosphomins ${ }^{\mathrm{TN}}$; Phosphotech, Saint Herblain, France) and soya lecithin (Ets Louis François, St Maur des Fossés, France).

†Per kg vitamin mixture: choline concentrate $50 \%, 200 \mathrm{~g}$; vitamin $\mathrm{E}(500 \mathrm{Ul} / \mathrm{g}), 10 \mathrm{~g}$; vitamin $\mathrm{D}_{3}(500000 \mathrm{Ul} / \mathrm{g}), 500 \mathrm{mg}$; vitamin $\mathrm{B}_{3}, 1 \mathrm{~g}$; vitamin $B_{5}, 2$ g; vitamin $B_{1}, 100 \mathrm{mg}$; vitamin $B_{2}, 400 \mathrm{mg}$; vitamin $B_{6}, 300 \mathrm{mg}$; vitamin $C, 20 \mathrm{~g}$; vitamin $B_{9}, 100 \mathrm{mg}$; vitamin concentrate $B_{12}(1 \mathrm{~g} / \mathrm{kg}), 1 \mathrm{~g}$; biotin, $1 \mathrm{~g}$; vitamin $\mathrm{K}_{3}, 1 \mathrm{~g}$; meso-inositol, $30 \mathrm{~g}$; cellulose, $732.1 \mathrm{~g}$.

‡Per kg mineral mixture: $\mathrm{KCl}, 90 \mathrm{~g} ; \mathrm{KIO}_{4}, 40 \mathrm{mg} ; \mathrm{CaHPO}_{4} \cdot 2 \mathrm{H}_{2} \mathrm{O}, 500 \mathrm{~g} ; \mathrm{NaCl}, 40 \mathrm{~g} ; \mathrm{CuSO}_{4} \cdot 5 \mathrm{H}_{2} \mathrm{O}, 3 \mathrm{~g} ; \mathrm{ZnSO}_{4} \cdot 7 \mathrm{H}_{2} \mathrm{O}, 4 \mathrm{~g} ; \mathrm{CoSO}_{4} \cdot 7 \mathrm{H}_{2} \mathrm{O}, 20 \mathrm{mg}$; $\mathrm{FeSO}_{4} \cdot 7 \mathrm{H}_{2} \mathrm{O}, 20 \mathrm{~g} ; \mathrm{MnSO}_{4} \cdot \mathrm{H}_{2} \mathrm{O}, 3 \mathrm{~g} ; \mathrm{CaCO}_{3}, 215 \mathrm{~g} ; \mathrm{MgSO}_{4} \cdot 7 \mathrm{H}_{2} \mathrm{O}, 124 \mathrm{~g} ; \mathrm{NaF}, 1 \mathrm{~g}$

$\S$ Calculated as: fat $\times 37.7 \mathrm{~J} / \mathrm{kg}$; protein $\times 16.7 \mathrm{~J} / \mathrm{kg}$.

For details of diets and procedures, see this page. 
sources, marine lecithin was used as a source of phospholipids including EPA and DHA, soyabean lecithin was a phospholipid devoid of EPA and DHA, and cod-liver oil was the source of neutral lipid including EPA and DHA. Diet names were chosen according to the percentage of dietary EPA and DHA contained in the phospholipid (PL diet) and neutral lipid (NL diet) fraction of the diet: PL5, PL3, PL1, NL1 and NL3. The marine phospholipid fraction in PL diets varied in inverse relation to soyabean lecithin, whereas NL diets contained soyabean lecithin in an inverse proportion to marine triacylglycerols (cod-liver oil). The composition of PL1 was close to a previously used one that had supported good growth and survival in European sea bass larvae (Cahu et al. $2003 \mathrm{~b}$ ) and was considered the control diet in the present study. Microdiets were processed as previously described (Cahu et al. $2003 b$ ) and pellet size was $200-400 \mu \mathrm{m}$. During the entire experimental period, larvae were continuously fed to excess for $24 \mathrm{~h}$ per $\mathrm{d}$ using a belt feeder. Food ingestion was monitored by observing the larval digestive tract under a binocular microscope, the dietary microparticles being visible by transparency. At the end of the trial ( $37 \mathrm{dph})$, fish can no longer be considered as larvae since this date corresponds to the transition from larvae to juveniles; consequently, experimental microdiets could not be used after this date considering that the particle size and the composition of the larvae feeds were not adapted to juveniles. Therefore, fish from the same experimental group were pooled and transferred to a 700-litre square fibreglass tank (one tank per diet) and reared until $71 \mathrm{dph}$ under the environmental conditions mentioned earlier. During this period, all fish were fed with the same commercial diet (Neo Soupra AL4; Le Gouessant, Lamballe, France) containing $58 \%$ protein, $13 \%$ lipid, $12 \%$ ash and $1.2 \%$ cellulose (proximate composition provided by the feed manufacturer). Food ingestion was monitored by observing digestive tracts of larvae under a binocular microscope.

\section{Sampling}

To evaluate growth, ten specimens were randomly sampled from each experimental tank (thirty larvae per experimental diet) at 12 , 16, 23, 30 and $37 \mathrm{dph}$, killed with an overdose of anaesthetic (tricaine methanesulfonate, MS 222) and their wet body weight measured to the nearest $0.1 \mathrm{mg}$. Fifty larvae were collected for mRNA studies from all experimental tanks at 16, 23, 30 and $37 \mathrm{dph}$, and total RNA immediately extracted. In all cases, sampling procedures were performed as previously described (Cahu et al. 2003b). The incidence of skeletal body malformations (splachnocranium, neurocranium and vertebral column deformities) was counted at $71 \mathrm{dph}$ (100 larvae per experimental diet; this developmental stage allows one to observe and identify correctly all deformities appearing during the larval period (before day 37)). It was not possible to determine real survival (percentage of surviving individuals in relation to the initial number of larvae) due to repetitive sampling; however, relative survival, expressed as the percentage of surviving fish fed on each diet in relation to the surviving specimens fed on the control diet (PL1), was calculated at $71 \mathrm{dph}$.

\section{RT-PCR analysis}

Different cDNA fragments of genes coding for RAR and for signalling molecules known to interact with the retinoic acid pathway were purified in European sea bass larvae by RT-PCR, cloned (Villeneuve et al. 2004), then sequenced and registered by the European Molecular Biology Laboratory: $R X R \alpha$ (accession number AJ 567907), $R A R \alpha$ (AJ 496189), RAR $\gamma$ (AJ 496181), BMP4 (AJ 567451) and IGF-I (AJ 579342). Glyceraldehyde-3phosphate dehydrogenase (GAPDH; AJ 567450) was chosen as the housekeeping gene (Table 2).

\section{Real-time RT-PCR}

cDNA samples were treated with DNase (AMP-D1; Sigma, St Louis, MO, USA) and real-time PCR was performed using the iCycler iQTM (Bio-Rad Laboratories Inc., Hercules, CA, USA). Quantitative PCR analyses for each gene were performed in a total volume of $15 \mu \mathrm{l}$ containing $5 \mu \mathrm{l}$ cDNA (dilution: $\left.10^{-3}\right), 1.5 \mu$ l fluorescein $(100 \mathrm{nmol} / \mathrm{l}$; Bio-Rad), $0.5 \mu \mathrm{l}$ primers $(10 \mu \mathrm{mol} / \mathrm{l})$ and $7.5 \mu \mathrm{l}$ QuantiTect SYBR Green PCR Master Mix 2X (QIAGEN GmbH, Hilden, Germany). For each target gene, forward and reverse primers (Table 3) were chosen in the sequences previously cloned. Thermal cycling was initiated with incubation at $95^{\circ} \mathrm{C}$ for $13.5 \mathrm{~min}$ for activation of HotStarTaq ${ }^{\mathrm{TM}}$ DNA polymerase. After this initial step, forty-five PCR cycles were performed. Each PCR cycle consisted of heating at $95^{\circ} \mathrm{C}$ for $30 \mathrm{~s}$ for denaturing, as well as at $60^{\circ} \mathrm{C}$ for $1 \mathrm{~min}$ for annealing and extension. Cycle threshold (CT) values corresponded to the number of cycles at which the fluorescence emission monitored in real time exceeded the threshold limit. Melting curve analysis was performed to confirm production of a single product in these reactions and the products were sequenced by MilleGen (Labège, France). Standard curves were established for each gene by plotting the $\mathrm{CT}$ values against the $\log _{10}$ of five different dilutions (in triplicate) of the cDNA sample solutions. Real-time PCR efficiency $(E)$ was determined for each gene from the slopes given by the Bio-Rad software according to the equation: $E=10^{(-1 /}$ slope). The relative expression ratio of each gene was calculated using REST $^{\odot}$ software (http://www.gene-quantification.info).

Table 2. Oligonucleotide primers used in PCR reactions

\begin{tabular}{lllc}
\hline Gene & \multicolumn{1}{c}{ Forward primer } & \multicolumn{1}{c}{ Reverse primer } & Annealing temperature $\left({ }^{\circ} \mathrm{C}\right)$ \\
\hline GAPDH & CAC CAC GCT CAC CAT CGC & CAT CTT GGG GAA CAT GTG & 54 \\
$R A R \alpha$ & ACC ACG CTC ACC ATC GC & ATC TTG GGG AAC ATG TG & 56 \\
$R A R \gamma$ & GAG GTG GGC ATG TCC AAG & ATC CAT CTC CAG GGG CAG & 58 \\
$R X R \alpha$ & TGC CAG TAC TGC CGC TAC & CAG CAT CTC CAT GAG GAA & 56 \\
$B M P 4$ & CCA GCC CGA GCC AAC A & CAC AAT CCA GTC ATT CCA & 52 \\
IGF-I & TAG CCA CAC CCT CTC ACT & ATG CCA AGA GCC CAA G & 54 \\
\hline
\end{tabular}

GAPDH, glyceraldehyde-3-phosphate dehydrogenase; RAR $\alpha$, retinoic acid receptor $\alpha$; RAR $\gamma$, retinoic acid receptor $\gamma$; RXR $\alpha$, retinoid $\mathrm{X}$ receptor $\alpha$; BMP4, bone morphogenetic protein-4; IGF-I, insulin-like growth factor-I. 
Table 3. Nucleotide sequences of the PCR primers used to assay gene expression by real-time quantitative PCR

\begin{tabular}{lllc}
\hline Gene & \multicolumn{1}{c}{ Forward primer } & \multicolumn{1}{c}{ Reverse primer } & PCR product length (nt) \\
\hline GAPDH & GAG GTC AAG GTT GAG GGT GA & CCA GTG GAC TCA ACC ACG TA & 125 \\
$R A R \alpha$ & CGC TAA ACC GAA CCC AGA & CTT CTC GGC CTG TTC CAA & 170 \\
$R A R \gamma$ & GCA AAG CTC ACC AAG AGA CC & GCG TAG TGA AGC CTG GTA GC & 180 \\
$R X R \alpha$ & CTG GTA GAG TGG GCC AAG AG & GTT CTG TGA GCA CCC TGT CA & 223 \\
$B M P 4$ & CTG CTC TCT TCC GCT GAA CT & GGC TCA CAC TAA AGC TCT CC & 205 \\
IGF-I & GTC TTG GCA GGT GCA CAG TA & ACA CGC TGC AGT TTG TGT GT & 157 \\
\hline
\end{tabular}

GAPDH, glyceraldehyde-3-phosphate dehydrogenase; RAR $\alpha$, retinoic acid receptor $\alpha$; RAR $\gamma$, retinoic acid receptor $\gamma$; RXR $\alpha$, retinoid X receptor $\alpha$; BMP4, bone morphogenetic protein-4; IGF-I, insulin-like growth factor-I.

The relative expression ratio for a considered gene is based on the PCR efficiency $(E)$ and the CT of a sample (PL3, PL5, NL1 or NL3) $v$. the control (PL1), and expressed in comparison to the reference gene $(G A P D H)$, according to Pfaffl's mathematical model (Pfaffl, 2001):

$$
\begin{aligned}
\text { Ratio }= & {\left[(E \text { gene })^{\Delta \mathrm{CT}} \text { gene }(\text { control-sample })\right] / } \\
& {\left[(E \text { GAPDH })^{\Delta \mathrm{CT} \quad G A P D H(\text { control-sample })}\right] . }
\end{aligned}
$$

Normalization relative to GAPDH provided a widely applicable value for comparative studies of gene expression at the mRNA level, since its expression is constant during activation and proliferation of cells (Gause \& Adamovicz, 1994).

\section{Statistical analyses}

Results are given as means and standard deviations. All data were checked for variance homogeneity using the Barlett's test (Dagnelie, 1975). Growth was compared by means of a one-way ANOVA followed by the Newman-Keuls multiple range test when significant differences were detected $(P<0 \cdot 05)$. Statistical differences in gene expression between the control and samples were evaluated in group means by randomization tests (Pfaffl et al. 2002) using $\operatorname{REST}^{\odot}$ software; 2000 random allocations were performed and significant differences were considered at $P=0 \cdot 05$.

\section{Results}

\section{Growth and survival}

Observation of larval digestive tracts under the binocular microscope revealed effective ingestion of the microparticulated diets in all groups. At the end of the rearing period ( $37 \mathrm{dph})$, statistically significant differences in larval growth were observed between experimental groups (ANOVA, $P<0 \cdot 05$, Fig. 1). Larvae fed diet PL3 exhibited the best growth performance, being $21.4 \%$ higher than that in the control group (PL1), and 25.7 and $49.7 \%$ higher in body weight than those fed PL5 and NL1, respectively. As the fish in the NL3 group died before $37 \mathrm{dph}$, their larval body weight could not be compared with those of the other experimental groups, although it was significantly lower at early stages of development (23 and $30 \mathrm{dph}$ ).

Compared with the control group (PL1), the relative survival was $226 \cdot 1,31.5$ and $128.7 \%$ in larvae fed PL3, PL5 and NL1, respectively. The best survival was observed in the group fed the PL3 diet ( $n$ 710).

\section{Skeletal malformations}

The incidence of skeletal malformations in European sea bass juveniles (age $71 \mathrm{dph}$, mean weight 2.4 (SD 0.59) g) is presented in Fig. 2. Almost half the fish fed the diet including the highest EPA + DHA concentration ( $4.8 \%$ in PL5) exhibited deformities. This value was very low $(6.6 \%)$ in the group fed the PL1 diet containing $1.1 \%$ EPA + DHA in the phospholipid fraction. Fish fed diets containing the two highest concentrations of EPA and DHA in the phospholipid fraction, PL5 and PL3, presented a high prevalence of scoliotic vertebral columns (35.3 and 10.2\%, respectively), while the other categories of skeletal malformations (deformities of the neurocranium, maxilla and operculum) were less frequent. Fish fed the diet NL1 containing the lowest level of EPA and DHA in the phospholipid fraction $(0 \cdot 3 \%)$ showed an equal percentage of skeletal malformations affecting the vertebral column and operculum (7.9 and $8.2 \%$, respectively); this percentage of deformities was higher than that observed in the control group.

\section{Effect of development on gene expression}

Only data concerning gene expression patterns in larvae fed PL1, the control group, were considered for evaluating gene expression

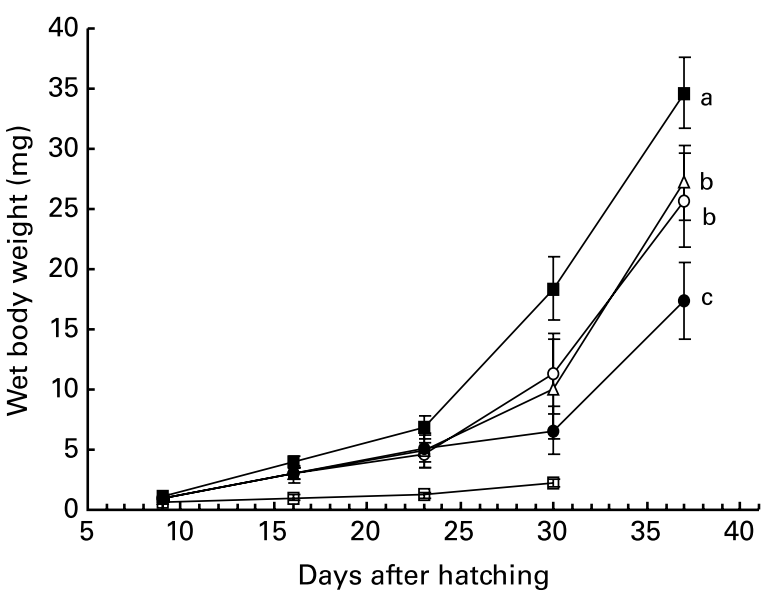

Fig. 1. Growth of European sea bass larvae fed isonitrogenous and isolipidic diets containing different levels of EPA and DHA. Diets were named according to the percentage of dietary EPA + DHA contained in the phospholipid $(\mathrm{PL})$ and neutral lipid (NL) fraction of the diet: PL5 (O), PL3 (घ), PL1 ( $\triangle$ ), NL1 $(\bullet)$ and NL3 ( $\square)$. Values are means with their standard deviations shown by vertical bars for three determinations on ten specimens. Mean values with unlike superscript letters were significantly different $(P<0.05)$. 


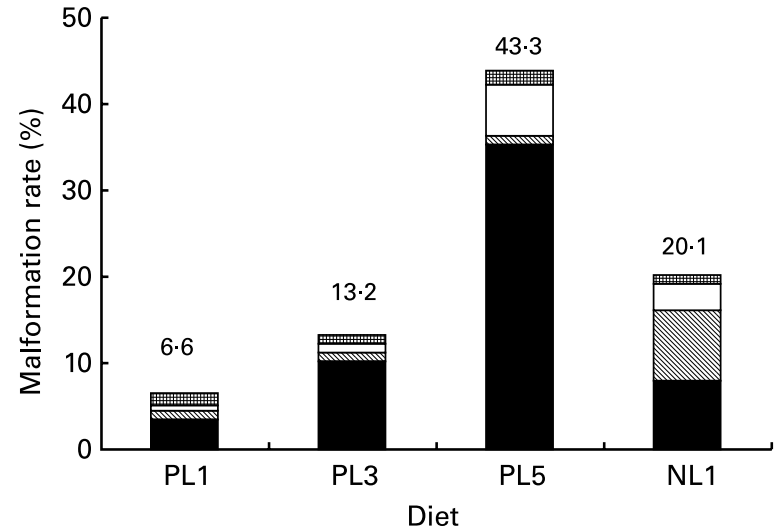

Fig. 2. Incidence of skeletal malformations ( $\square$, neurocranium; $\square$, maxilla; $\mathbb{\nabla}$, operculum; $\mathbf{\square}$, vertebral column) in European sea bass juveniles (age $71 \mathrm{~d}$ post-hatch; dph) fed isonitrogenous and isolipidic diets containing different levels of EPA and DHA. For details of experimental diets, see Table 1 and p. 878. As fish fed the NL3 diet died before $37 \mathrm{dph}$, their incidence of skeletal deformities could not be determined.

during development because these larvae were reared under standard nutritional conditions; therefore the expression patterns of genes studied in this experimental group could be considered normal. The expression of all the studied genes, except $R A R \alpha$, tended to decrease between 16 and $37 \mathrm{dph}$ but no significant difference was found $(P>0.05)$.

\section{Effect of experimental diets on gene expression}

At 16 dph, fish fed diet NL3 (Fig. 3 (a)) exhibited a significant upregulation of $R X R \alpha$ expression (up-regulation factor 3.06, $P<0.001)$ compared with the control group (PL1), while at $23 \mathrm{dph}, R A R \alpha, R A R \gamma, R X R \alpha$ and $B M P 4$ were significantly down-regulated by factors of $2 \cdot 9,3 \cdot 1,3 \cdot 0$ and $2 \cdot 0(P<0 \cdot 001)$, respectively. At $16 \mathrm{dph}$, larvae fed the NL1 diet (Fig. 3 (b)) showed a significant up-regulation of $R A R \alpha$ (up-regulation factor 6.8, $P<0 \cdot 001$ ), $R X R \alpha$ (up-regulation factor $2 \cdot 6, P<0 \cdot 01$ ) and $B M P 4$ (up-regulation factor $3 \cdot 8, P<0 \cdot 001$ ) expression compared with the control group, while no other differences were observed after this age. Similarly, significant differences were observed only at 16 dph in fish fed the PL5 diet (Fig. 3 (c)) compared with the PL1 group, but $R A R \alpha(P<0.01), R X R \alpha(P<0.001)$ and $I G F-I(P<0 \cdot 001)$ were $3.5,3.5$ and 4.5 times down-regulated, respectively. The PL3 diet (Fig. 3 (d)) did not seem to have any effect on larval gene expression compared with the PL1 diet.

\section{Discussion}

For many years, the development of a dry microdiet for first-feeding marine fish larvae that sustains good growth, survival and harmonious development has been the major objective of many laboratories. In this sense, the determination of dietary requirements has shown that different nutrients directly influence larval growth and skeletal development. Recently, it has been shown that the dietary phospholipid level and phospholipid:neutral lipid value are influential for European sea bass development (Cahu et al. 2003b). The effect of different dietary levels of PUFA and their form of supply in the phospholipid and neutral lipid fraction on European sea bass larvae still remained to be determined. Moreover, we were interested in assessing the poss-
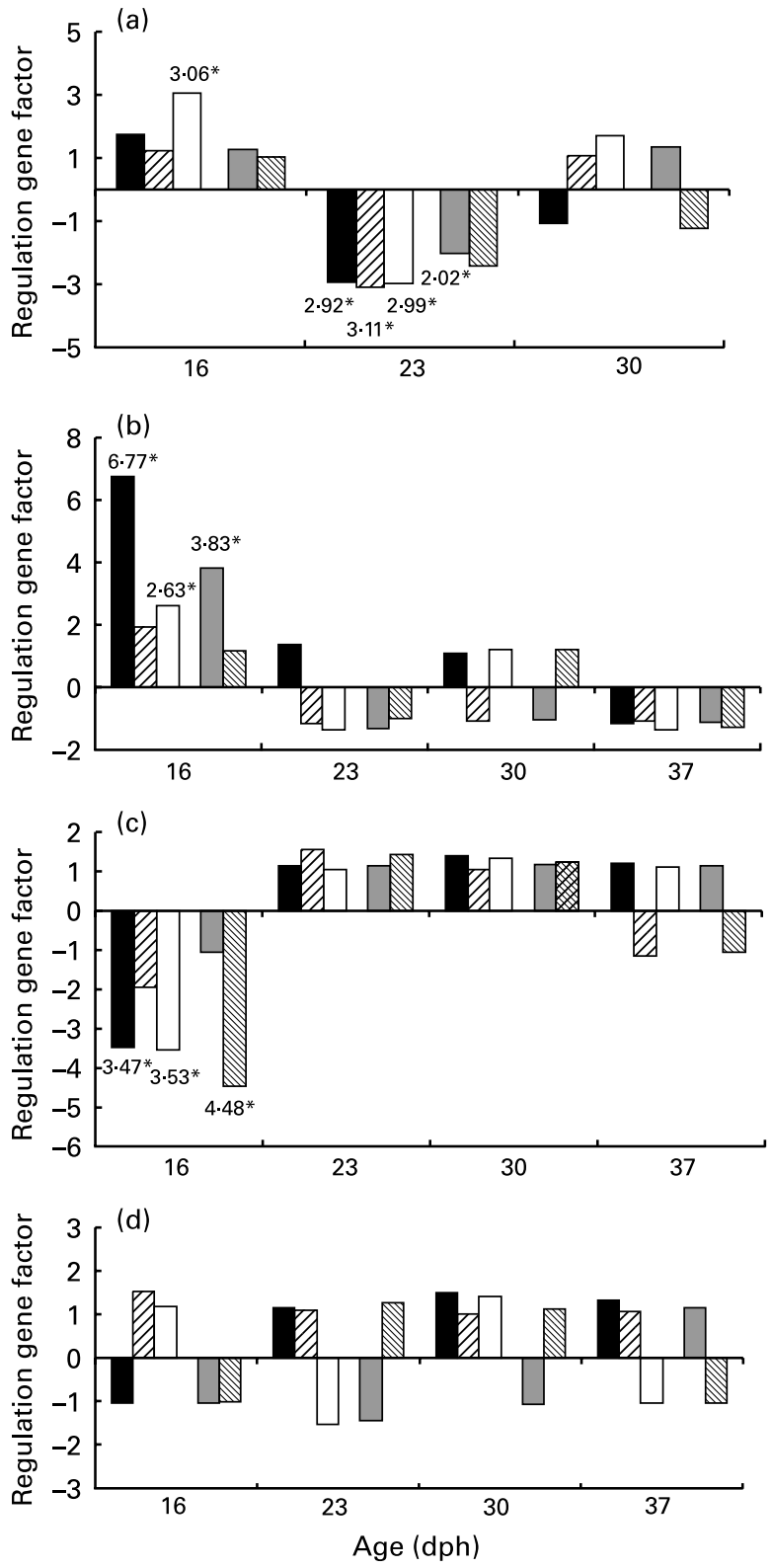

Fig. 3. Regulation gene factor for retinoic acid receptor $\alpha(\square)$, retinoic acid receptor $\gamma(\mathbb{Z})$, retinoid $X$ receptor $\alpha(\square)$, bone morphogenetic protein- $4(\square)$ and insulin-like growth factor-I $(\mathbb{\nabla})$ in European sea bass larvae (dph, days post-hatch) fed NL3 (a), NL1 (b), PL5 (c) and PL3 (d) diets. For details of experimental diets, see Table 1 and p. 878. Plotted data are means of four determinations. Mean values were significantly different between fish fed experimental diets and the control group (PL1): ${ }^{\star} P<0.05$.

ible interaction between the PUFA pathway and the retinoid pathway, both of which are involved in morphogenic processes.

Good growth and survival has been obtained with a compound microdiet containing $11 \%$ phospholipids (Cahu et al. 2003b). This value was used in the current study to formulate experimental diets with an appropriate level of phospholipids (PL5, PL3, PL1 and NL1 diets). However, although the NL3 diet only contained $8 \%$ phospholipids, this percentage was still acceptable in terms of growth and larval survival rates (Cahu et al. 2003b). The tested diets, differing by the source and concentration of PUFA, greatly affected both growth and survival of European 
sea bass larvae. The diet containing a moderate level of EPA and DHA in the phospholipid fraction (PL3) induced the best growth and survival, while the diet with a similar level of EPA and DHA in the neutral lipid fraction (NL3) was lethal for sea bass larvae. A higher percentage of EPA and DHA in the phospholipid fraction (PL5) negatively affected growth, survival and the incidence of skeletal malformations in larvae. Observed differences in growth performance between larvae fed low rates of dietary EPA and DHA depended on the supply form of both essential fatty acids: when they were in the phospholipid fraction (PL1) good growth was observed, while growth was lower when they were in the neutral lipid fraction. These results strengthen the fact that the phospholipid fraction is more efficient than the neutral lipid fraction to supply $n$-3 PUFA in developing larvae.

Little is known about the optimal DHA:EPA ratio for first-feeding marine larvae. The lipid composition of eggs/yolk reserves has been suggested as an indicator for determining the nutritional requirements of newly hatched larvae. Typically a dietary DHA:EPA ratio of 2:1 is found in marine species, and thus has been suggested as adequate for larval nutrition (Sargent et al. 1997). Total DHA:EPA ratios in PL diets were very similar (1.9:1, 2.2:1 and $2 \cdot 4: 1$ in PL1, PL3 and PL5 diets, respectively) and slightly higher than those of NL diets $(1 \cdot 8: 1$ in NL1 and NL3 diets). It has been suggested that marine fish larval diets with DHA:EPA less than or equal to 1 are sub-optimal, either by not providing sufficient DHA or by providing an undesirable excess of EPA (Sargent et al. 1997). Therefore, the differences observed in growth and survival of European sea bass in the present study could not be attributed to inappropriate DHA:EPA ratios. Here, the DHA:EPA that promoted the highest growth rate and survival in European sea bass fell in the range of recommended values for gilthead sea bream and red drum, which are 2:1 and $>2.5: 1$, respectively (Brinkmeyer \& Holt, 1998; Rodriguez et al. 1998), indicating similar essential fatty acid requirements for this group of species.

Our results demonstrated the existence of a direct relationship between the amount of $n-3$ PUFA in phospholipids and the effect on the normal development of the skeleton during the larval stage. An effect of oxidation of PUFA could be evoked (Sargent et al. 2002) but it is unlikely that the observed skeletal abnormalities resulted from an oxidation of PUFA in the microparticles since the formulation of the experimental diets falls within the range of recommended levels for dietary antioxidants, such as vitamin E ( $\alpha$-tocopherol) and ascorbic acid (National Research Council, 1993).

Then, a direct effect of $n-3$ PUFA on skeletal development must be considered. A previous study (Villeneuve et al. 2005) showed that skeletal malformations induced in European sea bass larvae by a nutritional factor, vitamin A, could be related to the expression of genes involved in their development, such as $R A R \alpha, R A R \gamma, R X R \alpha$. In the present study, European sea bass larvae fed the NL3 diet exhibited a significant up-regulation of $R X R \alpha$ expression at $16 \mathrm{dph}$ compared with the control group. This diet contained a high proportion of neutral lipids, which are less efficient for fish larvae than phospholipids. It has been previously demonstrated that several PUFA can activate $R X R \alpha$ expression, while the strongest up-regulation was obtained with DHA in rats (Mata de Urquiza et al. 2000). Moreover, a direct activation of the transcription of $R X R \alpha$ by several fatty acids has been shown experimentally (Steineger et al. 1998), which supports the idea that under the present experimental conditions, the high level of cellular PUFA present in the neutral lipid fraction in the NL3 group directly stimulated the transcription level of $R X R \alpha$. Fish fed diet NL1 also exhibited a significant up-regulation of $R X R \alpha$ at $16 \mathrm{dph}$. It is well known that $R X R \alpha$ preferentially binds the $\alpha$ isoform of RAR (Ross et al. 2000; Egea et al. 2001 ), so the increase of $R X R \alpha$ could lead to the up-regulation of $R A R \alpha$ and these two kinds of receptors might have formed active dimers. The up-regulation of RAR $\alpha$ was not revealed in the NL3 group and this might be due to their poor nutritional status. Several studies have demonstrated that the retinoic acid pathway and BMP4 can synergize to induce apoptosis (Glozak \& Rogers, 1998). BMP4 does not seem to have a RARE in its nucleotide sequence (Balmer \& Blomhoff, 2002), but its activation by retinoic acid would require a gene-specific activator, which is still unknown (Thompson et al. 2003). This hypothesis suggests that, in the present study, a possible apoptosis induced by lipids in an inappropriate form interfered with the normal differentiation processes of the larvae, leading to a high rate of malformations in fish fed the NL1 diet and the death of specimens in the NL3 experimental group. In the NL3 group, fish were close to death and this might explain the significant down-regulation of $R A R \alpha$, $R A R \gamma, R X R \alpha$ and $B M P 4$ at the age of $23 \mathrm{dph}$.

Concerning larvae fed PL5, we noted that the diet exerted an antagonist effect on gene expression at $16 \mathrm{dph}$ in comparison to the NL1 group. Instead of an up-regulation, we observed a down-regulation of $R A R \alpha, R X R \alpha$ and $I G F-I$. It is interesting to note that the $R A R \alpha$ expression pattern also followed the one of $R X R \alpha$. The PL5 diet contained a high concentration of $n-3$ PUFA, mainly in the phospholipid fraction, and as fish fed this diet exhibited a retardation of growth and not an optimal rate of survival, we might assume that this concentration of dietary $n-3$ PUFA was excessive. Thus, it can be hypothesized that under the present experimental conditions, the high rate of dietary PUFA certainly activated the expression of PPAR (Kliewer et al. 1997). PPAR are known to interact with RXR and the heterodimerization of PPAR with RXR indicates that the retinoid and peroxisome proliferator signalling pathways converge through the direct interaction of their respective nuclear receptors (Bonilla et al. 2000) and they might have activated the expression of target genes. Assay on PPAR is necessary for further speculations and to confirm our present results.

Under stress conditions, glucocorticoids stimulate $R X R \alpha$ transcription level (Steineger et al. 1998). They also stimulate PPAR expression and PPAR regulate genes involved in the activation of fatty acids to mobilize fatty acids and maintain energy homeostasis (Lemberger et al. 1996). Considering these results reported in the literature, we might assume that $n$ - 3 PUFA present in the PL5 diet highly stimulated PPAR transcription, creating a state of nutritional stress. This hypothesis was reinforced by histological observations (data reported in Gisbert et al. 2005) showing an important accumulation of lipids in the enterocytes. As the proportion of intracellular $n$-3 PUFA was very high, the rate of PPAR transcription might have been elevated, leading to an excessive number of PPAR in the cell and consequently to an excess of PPAR/RXR $\alpha$ heterodimers. Thus, a negative feedback of these molecules on the $R X R \alpha$ gene might explain its lower transcription level in larvae aged $16 \mathrm{dph}$ fed on PL5. Furthermore, this repression of $R X R \alpha$ was observed concurrently with the down-regulation of its partner $R A R \alpha$. IGF-I has a high probability to possess a RARE in its promoting region (Balmer \& Blomhoff, 2002) and several studies have demonstrated that retinoic acid 
influences its transcription level (Gabbitas \& Canalis, 1997; Fu et al. 2001). Thus, we might suppose that $R X R \alpha$ down-regulation indirectly led to $I G F-I$ down-regulation through $R A R \alpha$ repression, resulting in a high percentage of skeletal deformities $(43.3 \%)$, which mainly affected the vertebral axis of fish. It is interesting to note that the malformations observed in the present study mainly affected the vertebral column, while in a previous study (Villeneuve et al. 2005) skeletal deformities induced by vitamin A were preferentially localized in the cephalic region. This might indicate that peroxisome proliferator and retinoid pathways involve two different cascades of morphogenetic genes. Further experiments would be necessary to study the expression pattern of PPAR and to assess their implication in morphogenesis processes in sea bass larvae.

In conclusion, the quantity and the form of EPA and DHA supply (neutral lipid or phospholipid) in diets are determining for European sea bass larval development. Larvae used EPA and DHA more efficiently when present in the phospholipid fraction: $1.1 \% \mathrm{EPA}+\mathrm{DHA}$ (corresponding to a total DHA:EPA ratio of 1.9:1) appeared optimal since it induced a low level of malformations. Better growth and survival of larvae can be obtained with higher EPA + DHA levels but to the detriment of morphogenesis. An excess of these fatty acids (PL5 diet) induced severe skeletal malformations. High levels of skeletal deformities and a reduction in growth and survival were associated with a down-regulation in $R X R \alpha, R A R \alpha, R A R \gamma$ and $B M P 4$ expression. High levels of dietary triacylglycerols (NL3 diet) up-regulated the expression of $R X R \alpha$ at early stages of development (16 dph), disrupting normal larval development and adversely influencing fish viability.

\section{Acknowledgements}

The authors wish to thank M. M. Le Gall and H. Le Delliou for their excellent technical assistance during larval rearing and sample analysis. L. V. and E. G. were supported by an IFREMER-INRA grant and EC Marie Curie Individual Fellowship (QLK-CT-2001-52009), respectively.

\section{References}

Andrades JA, Becerra J \& Fernandez-Llebrez P (1994) Skeletal deformities of the gilthead sea bream (Sparus aurata L.): study of the subcommisural organ (SCO) and Reissner's fiber (RF). Anat Anz 174, $381-383$.

Balmer JE \& Blomhoff R (2002) Gene expression regulation by retinoic acid. J Lipid Res 43, 1773-1808.

Boglione C, Gagliardi F, Scardi M \& Cataudella S (2001) Skeletal descriptors and quality assessment in larvae and post-larvae of wildcaught and hatchery-reared gilthead sea bream (Sparus aurata L. 1758). Aquaculture 192, 1-22.

Bonilla S, Redonnet A, Noël-Suberville C, Pallet V, Garcin H \& Higueret $P$ (2000) High-fat diets affect the expression of nuclear retinoic acid receptor in rat liver. Br J Nutr 83, 665-671.

Brinkmeyer R \& Holt GJ (1998) Highly unsaturated fatty acids in diets for red drum (Scianops ocellatus) larvae. Aquaculture 161, 253-268.

Cahu C, Zambonino-Infante J \& Takeuchi T (2003a) Nutritional components affecting skeletal development in fish larvae. Aquaculture 227, 245-258.

Cahu CL, Zambonino Infante JL \& Barbosa V (2003b) Effect of dietary phospholipid level and phospholipid:neutral lipid value on the development of sea bass (Dicentrarchus labrax) larvae fed a compound diet. Br J Nutr 90, 21-28.

Dagnelie P (1975) Les méthodes de l'inférence statistique. In Théorie et méthodes statistiques, vol. 2, pp. 1-463 [J Ducolot, editor]. Belgium: Les Presses Agronomiques de Gembloux.

Egea PF, Rochel N, Birck C, Vachette P, Timmins PA \& Moras D (2001) Effects of ligand binding on the association and conformation in solution of retinoic acid receptors RXR and RAR. J Mol Biol 307, $557-576$.

Fu Z, Noguchi T \& Kato H (2001) Vitamin A deficiency reduces insulin-like growth factor (IGF)-I gene expression and increases IGF-I receptor and insulin receptor gene expression in tissues of Japanese quail (Coturnix coturnix japonica). J Nutr 131, 1189-1194.

Gabbitas B \& Canalis E (1997) Retinoic acid regulates the expression of insulin-like growth factors I and II in osteoblasts. J Cell Physiol 172, $253-264$.

Gause WC \& Adamovicz J (1994) The use of the PCR to quantitate gene expression. PCR Methods Appl 3, 123-135.

Gisbert E, Villeneuve L, Zambonino-Infante JL, Quazuguel P \& Cahu CL (2005) Dietary phospholipids are more efficient than neutral lipids for long chain polyunsaturated fatty acid supply in European sea bass Dicentrarchus labrax larval development. Lipids 40, 609-618.

Glozak MA \& Rogers MB (1998) BMP4 and RA-induced apoptosis is mediated through the activation of retinoic acid receptors $\alpha$ and $\gamma$ in P19 embryonal carcinoma cells. Exp Cell Res 242, 165-173.

Kliewer SA, Sundseth SS, Jones SA, et al. (1997) Fatty acids and eicosanoids regulate gene expression through direct interactions with peroxisome proliferator-activated receptors $\alpha$ and $\gamma$. Proc Natl Acad Sci USA 94, 4318-4323.

Krumlauf R (1994) Hox genes in vertebrate development. Cell 78, 191-201.

Lemberger T, Saladin R, Vásquez M, Assimacopoulos F, Staels B, Desvergne B, Wahli W \& Auwerx J (1996) Expression of the peroxisome proliferator-activated receptor $\alpha$ gene is stimulated by stress and follows a diurnal rhythm. J Biol Chem 271, 1764-1769.

Mata de Urquiza A, Liu S, Sjöberg M, Zetterström RH, Griffiths W, Sjöval J \& Perlmann T (2000) Docosahexaenoic acid, a ligand for the retinoid X receptor in mouse brain. Science 290, 2140-2144.

National Research Council (1985) Guide for the Care and Use of Laboratory Animals, Publication no. 85-23 (rev.). Bethesda, MD: National Institutes of Health.

National Research Council (1993) Nutrient Requirements of Fish. Washington, DC: National Academy Press.

Ogura T \& Evans RM (1995) A retinoic acid-triggered cascade of HOXB1 gene activation. Proc Natl Acad Sci USA 92, 387-391.

Pfaffl MW (2001) A new mathematical model for relative quantification in real-time RT-PCR. Nucleic Acids Res 29, 2002-2007.

Pfaffl MW, Horgan GW \& Dempfle L (2002) Relative expression software tool $\left(\mathrm{REST}^{\mathcal{O}}\right)$ for group-wise comparison and statistical analysis of relative expression results in real-time PCR. Nucleic Acids Res 30, 9-36.

Rodriguez C, Perez JA, Badia P, Izquierdo MS, Fernández-Palacios H \& Hernández AL (1998) The $n$-3 highly unsaturated fatty acids requirements of gilthead sea bream (Sparus aurata L.) larvae when using an appropriate ratio in the diet. Aquaculture 169, 9-23.

Ross SA, McCaffery PJ, Drager UC \& De Luca LM (2000) Retinoids in embryonal development. Physiol Rev 80, 1021-1054.

Sargent JR, McEvoy LA \& Bell JG (1997) Requirements, presentation and sources of polyunsaturated fatty acids in marine larval fish. Aquaculture 155, 117-127.

Sargent J, McEvoy L, Estevez A, Bell G, Bell M, Henderson J \& Tocher D (1999) Lipid nutrition of marine fish during early development: current status and future directions. Aquaculture 179, 217-229.

Sargent JR, Tocher DR \& Bell JG (2002) The lipids. In Fish Nutrition, 3rd ed., pp. 182-259 [JE Halver and RW Hardy, editors]. London: Academic Press. 
Sasagawa S, Takabatake T, Takabatake Y, Muramatsu T \& Takeshima K (2002) Axes establishment during eye morphogenesis in Xenopus by coordinate and antagonistic actions of BMP4, shh, and RA. Genesis 33, 86-96.

Steineger HH, Arnsten BM, Spydevold Ø \& Sørensen HN (1998) Gene transcription of the retinoid $\mathrm{X}$ receptor $\alpha(\mathrm{RXR} \alpha)$ is regulated by fatty acids and hormones in rat hepatic cells. J Lipid Res 39, 744-754.

Suzuki T, Oohara I \& Kurokawa T (1998) Hoxd-4 expression during pharyngeal arch development in flounder (Paralichthys olivaceus) embryos and effects of retinoic acid on expression. Zool Sci 15, 57-67.

Thompson DL, Gerlach-Banck LM, Barald KF \& Koenig RJ (2003) Retinoic acid repression of bone morphogenetic protein 4 in inner ear development. Mol Cell Biol 23, 2277-2286.
Villeneuve L, Gisbert E, Cahu CL, Le Gall MM \& Zambonino-Infante JL (2004) Expression and localization of some retinoid receptors during European sea bass (Dicentrarchus labrax) larvae development. Aquaculture 242, 537-551.

Villeneuve L, Gisbert E, Le Delliou H, Cahu CL \& Zambonino-Infante JL (2005) Dietary levels of all-trans retinol affect retinoid nuclear receptor expression and skeletal development in European sea bass larvae. $\mathrm{Br} \mathrm{J}$ Nutr 93, 791-801.

Zambonino-Infante JL, Cahu CL \& Péres A (1997) Partial substitution of di- and tripeptides for native protein in sea bass diet improves Dicentrarchus labrax larval development. J Nutr 127, 604-614. 